\title{
OLDER WORKERS ARE WILLING AND EAGER TO LEARN NEW SKILLS
}

Hispanic/Latino and African American/Black interest leads the way

\section{Two-thirds of older workers are interested in additional job/skills training.}

Interest is even higher among:

\section{$74 \%$}

African American/Blacks

\section{$82 \%$}

Hispanics/Latinos

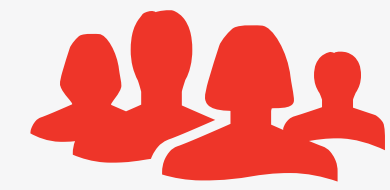

Interest in training

increased with employer support.

\section{$94 \%$}

are willing to learn new skills if requested by a current or potential employer.

\section{$97 \%$}

Willingness is highest - and near universal - for Hispanics/Latinos.

Two-thirds of older workers have taken some type of skills training in the past two years. Most commonly:
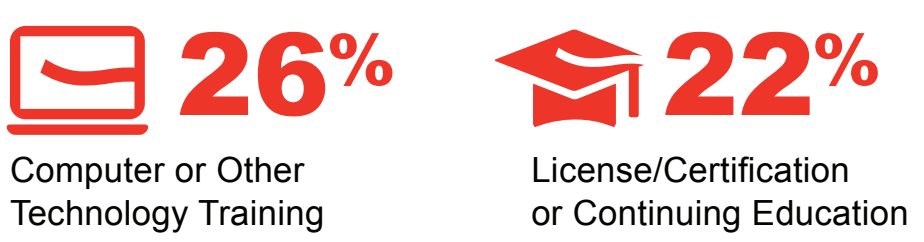
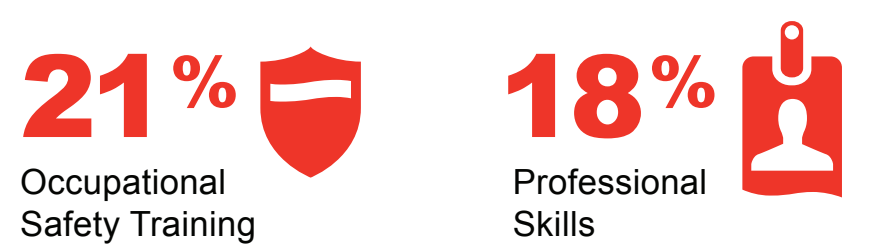

While technical skills and digital literacy remain very much in demand, human or soft - skills are rapidly increasing in importance.

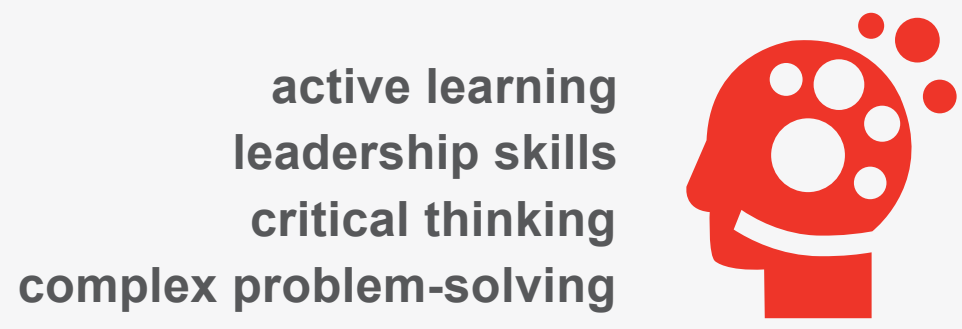

Excerpt from The World Economic Forum's* list of top 15 skills for 2025

Older workers have not only focused on those types of skills in previous trainings, but also show very strong interest in acquiring them in the next year.

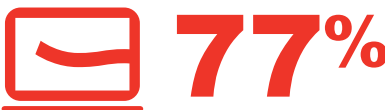

Computer or Other Technology Training

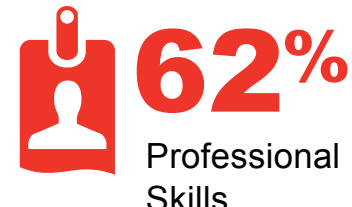
Skills

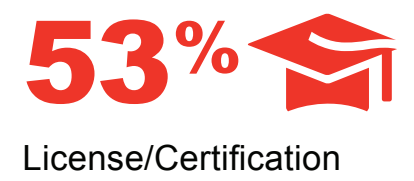

or Continuing Education

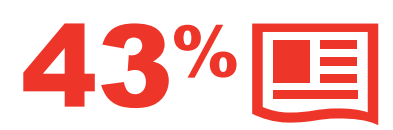

Industry-specific skills and certifications

African Americans/Blacks and Hispanics/Latinos are even more eager than White workers to expand these in-demand skill sets.

$$
\text { african American/Black Hispanic/Latino White }
$$

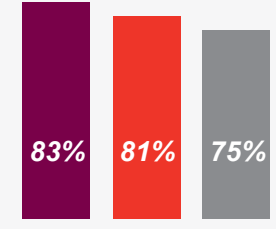

Computer or Other Technology Training

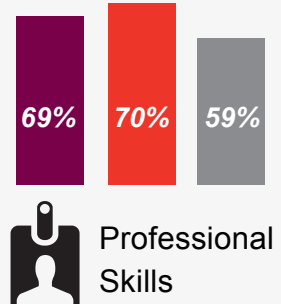

$\Omega$ Skills

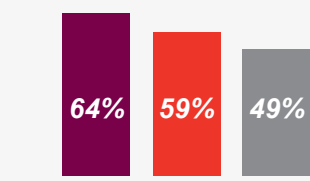

$\mathcal{Y}$ License/Certification Eduction Education 